\title{
RITUALES FUNERARIOS
}

\author{
Marta Allué Martínez \\ Institut Català d'Antropologia, Tarragona
}


La Guía para el estudio de los rituales funerarios que presentamos queda subordinada a las restantes guias para la investigación etnográfica ya publicadas en el primer número de Arxiu d'Etnografia de Catalunya.

La presente guia, como las anteriores, está dirigida a todo aquel investigador que se interese por el análisis del ritual funerario desde una perspectiva cronológica y es adaptable, por tanto, a intereses folklóricos así como etnográficos y etnológicos. La guia es orientativa puesto que marca las líneas generales del trabajo a realizar y puede ser utilizada como instrumento para la clasificación de datos procedentes tanto de la investigación de campo como del sondeo bibliográfico.

Otra de las características del cuestionario es su presentación como alternativa renovada de análisis frente a los manuales ya publicados, que ofrecían una clasificación de datos únicamente orientada al estudio de las sociedades primitivas o bien, como los casos del Manual d'Etnografia i Folklore de 1922 y la Guia del Ateneo de Madrid (1901), cuyo objetivo se centraba en la búsqueda de datos insólitos y exóticos referentes al folklore funerario de la vida tradicional.

Nuestro cuestionario combina entradas ya conocidas por la Etnografía clásica son otras fruto de una orientación teórica personal avalada por un trabajo de campo previo, lo cual dará cabida a una serie de datos informativos de difícil ubicación en los cuestionarios publicados hasta el momento. 
El presupuesto metodólogico que ampara la concepción de la siguiente guia es extraordinariamente simple y se basa en la descripción cronológica de los hechos lo cual corresponde, en líneas generales, a los esquemas teóricos presentados por diferentes autores en torno a los ritos de paso.

La muerte es objeto de un ritual de separación por medio del cual, en nuestras culturas, el individuo pasa a un nuevo estatus ya definitivo, incorporándose a un mundo que no es de los vivos y que genera: 1) una serie de actitudes y formas de conducta culturalmente establecidas; 2) un cambio en los procesos de interación a nivel familiar y social; y 3) una ideologia resultante que puede explicarse a través de los hechos descritos a ser vehículo de análisis del resto.de los componentes de una cultura.

Este planteamiento supone que el proceso ritual puede ser ajustado al esquema tripartito de los rituales de crisis de vida, marcado por una fase previa de separación que comienza a partir del momento en que se supone que el enfermo va a morir, finalizando con los ceremoniales de separación que suponen la despedida del ser querido y la constatación de la muerte. Posteriormente se inicia la segunda fase, durante la cual el carácter liminal de los ceremoniales se hace más patente y finaliza con la inhumación del cadáver en el cementerio. Durante esta fase, las actitudes de los vivos frente al difunto y el simbolismo de los actos rituales reflejan la situación liminal del objeto central del rito: el cadáver. Con la incorporación del muerto a su nuevo estatus por la finalización de los actos rituales, la situación liminal en torno al cadáver desparece, manteniéndose la situación entre los supervivientes, que viene reflejada simbólicamente a trevés del luto, hecho que prolonga el período liminal del proceso ritual.

Los aspectos marginales relacionados con el proceso ritual, como es el caso del luto o de las commemoraciones de difuntos, quedan dentro del repertorio de la guia, por guardar algunos de ellos estrecha relación con el significado de la muerte, y figuran por tanto al final del cuestionario.

Finalmente, cabe decir, que un segundo y último objetivo implicito en esta guia, apunta hacia la posibilidad de que mediante la descripción etnográfica de prácticas rituales en decadencia y su sustitución por nuevas formas más asépticas de tratamiento de la muerte, podamos establecer cuáles son las directrices de cambio que se es- tán operando en la actualidad a estos niveles, para asi darle una estructura renovada a las descripciones clásicas.

\section{FASE PRE-LIMINAR}

1. PReVenciones ante la muerte. prácticas previas al OBITO

\subsection{Consuetudinarias:}

11.1. Adquisición en vida de la sepultura, mortaja, féretro u otos objetos de carácter funerario.

1.1.2. Expresiones de última voluntad dirigidas a los miembros de la familia o a la red social.

1.1.3. Adscripción a cofradias $u$ otras instituciones que otorguen derecho a servicios especiales en caso de muerte.

1.1.4. Otras costumbres.

\subsection{Testamentarias:}

1.2.1. Frecuencia de los casos en los que existan disposiciones testamentarias o defunciones "ab intestato" (Consejo de parientes).

1.2.2. Clases de testamentos, las corrientemente utilizadas en la localidad.

1.2.3. Disposiciones testamentarias más frecuentes respecto al fuDisposas, institución de heredero, tutela, legados o cualquiera otras concernientes ala persona o a la propiedad.

12.4. Bienes $u$ objetos de que no dispone el testador en su testamento, pero que por costumbre pasen a su muerte a poder de determinadas personas. Formalidades en la entrega de estos bienes u objetos.

1.2.5. Referencia en el testamento a la condición religiosa o política del testador.

\subsection{Presagios y pronósticos de muerte:}

1.3.1. Presagios: señales 0 indicadores de carácter sobrenatural que indiquen la proximidad de una muerte (presencia de animales depredadores, moscardones, etc.)

1.3.2. Pronósticos: reconocimiento de la proximidad de la muerte 
en un individuo enfermo a través de signos y simbolos de carácter sobrenatural.

1.3.3. Tentativas para aplazar la muerte.

\subsection{Preparación del moribundo para la defunción:}

1.4.1. Traslado de la casa a otro lugar (hospital, asilo, etc.). Motivos.

1.4.2. Traslado del hospital a casa. Motivos. 1.4.3. Permanencia en la institución hospitalaria hasta el óbito. Mo-
tivos.

1.4.4. Vestido del enfermo-moribundo con atuendos mortuorios.

1.4.5. Preparación del dormitorio para la muerte o para recibir los úlimos sacramentos: cirios, objetos sagrađos de la familia o

1.4.6. Adas cofradias que se reservan para tales momentos.

viático. 1.4.7. Interacción familiar y social durante la agonia. Personas que
asisten y actitudes.

1.4.8. Toque de agonía. Número de campanadas.

\section{FASE LIMINAR}

\section{MUERTE, VELATORIO Y ENTIERRO}

\subsection{Defunción:}

2.1.1. Criterios para declarar la defunción. Prácticas más usuales: coma, cese de la respiración, cese de los latidos, muerte ce. rebral, etc.

2.1.2. Intentos para hacer revivir al difunto. Prácticas tradicionales no médicas.

2.1.3. Reacciones ante la muerte: lamentaciones, huida, ataques de tipo "histérico" culturalmente establecidos, etc.

\subsection{Avisos de fallecimiento:}

2.2.1. Las campanadas.

2.2.2. Comunicación interpersonal.

2.2.3. Avisos simbólicos (crespones, banderas a media asta, etc.)

2.2.4. Avisos escritos: esquelas y carteles. Avisos radiofónicos.

\subsection{Equipo funerario:}

2.3.1. Los vestidores-as: profesionales, vecinos o familiares.

2.3.2. Mortaja. Tipos.

2.3.3. Técnicas de presentación del cadáver: refrigeración, inyección de sustancias conservantes, ataúdes especiales, embalsamiento, etc.

2.3.4. Prácticas, creencias y supersticiones relativas a la manera de dejar el cuerpo del difunto: exposición abierta, cubierto, en una habitación iluminada o a oscuras, en "actitud de vivo", en "actitud de muerto"...

2.3.5. Solicitudes al respecto por parte de los familiares en el caso de que sea vestido en el hospital y conducido a la "morgue" del mismo.

2.3.6. Escenografía del hogar o de la alcoba para el velatorio.

\subsection{El velatorio}

2.4.1. Actitudes ante el cadáver: familiares, amigos y vecinos.

2.4.2. Asistentes, tanto en el hogar como en la "morgue" hospitalaria.

2.4.3. Expresiones de dolor y temas de conversación.

2.4.4. Refrigerio durante el velatorio.

2.4.5. Medidas para evitar otras muertes, (prácticas rituales y supersticiosas)

\subsection{Entierro:}

2.5.1. Determinación del momento,lugar y forma del entierro. Disposiciones concretas por parte de los familiares; disposiciones habituales cuando se hace cargo de ello una compañia de pompas fúnebres.

2.5.2. Lugar de la casa por donde sale el cadáver.

2.5.3. Ceremonias particulares a la salida del cadáver de la casa.

2.5.4. Conducción del cadáver de la casa o del hospital a la iglesia; omisión de este recorrido y otras disposiciones.

2.5.5. Forma de conducción: a hombros y caminando, en un coche fúnebre especial,etc.

2.5.6. Cortejo de entierro. Disposición de los participantes en relación al féretro, a pie o en automóvil.

2.5.7. Luto en la ceremonia fúnebre u otro tipo de objetos especia- 
les (medallas, escapularios, cruces, etc.) utilizados para esa ceremonia.

2.5.8. En la iglesia. Tipo de ceremonia litúrgica celebrada: oficio eucarístico o bien resposo con homilia.

2.5.9. Disposición del cadaver en la iglesia o fuera de ella y su relación con la disposición de los familiares y demás asistentes.

2.5.10. Caracteristicas del pésame en la iglesia o fuera de ella. Diferenciación o no en el ritual en función del sexo.

2.5.11. El camino al cementerio. Asistentes y configuración de la comitiva.

2.5.12. En el cementerio. Actos ceremoniales previos al cierre de la fosa o el nicho, ya sean sagrados o profanos.

2.5.13 Momento en que se abandona el cementerio: tras el cierre de la tumba, durante o previamente al instante. Motivos.

\section{FESE POST-LIMINAR}

\section{PRACTICAS POSTERIORES AL ENTIERRO.}

3.1. Regreso del duelo a la casa mortuoria.

3.2. Comida o banquete funerario.

3.3. Prácticas religiosas:

3.3.1. Misas y funeral que se ofrecen por el difunto. Tiempo que transcurre hasta su celebración.

3.3.2. Ofrendas de alimentos en los ofertorios de las misas tras el fallecimiento.

3.3.3. Rezos familiares en la casa por el alma del difunto.

3.3.4. Limosnas.

3.3.5. Indulgencias.

\subsection{Prácticas profanas:}

3.4.1. Disposición de fotografias y objetos personales del difunto en un lugar destacado de la casa.

3.4.2. Actos en honor al difunto: preparación de un lugar en la mesa para el difunto, por ejemplo.

3.4.3. Reparto ritual de los bienes personales del difunto.

3.4.4. Prevenciones de otras muertes o ritual purificador tras la incorporación del difunto: cremación de objetos personales o de los que hubieran estado en contacto con el difunto.

\section{CONMEMORACIONES DE DIFUNTOS}

4.1. Fiesta de difuntos $\left(1^{\circ}\right.$ de noviembre)

4.2. Miércoles de Ceniza

4.3. Viernes Santo

4.4. Otras fechas señaladas en las que se recuerde a los difuntos.

\section{EL LUTO}

5.1. Duración del luto en relación o no con la proximidad de parentesco.

5.2. Ropas, ornamentos y colores

5.3. Comportamientos sociales, señales y objetos de luto.

5.4. Duración del luto y su relación con las visitas al cementerio.

\section{RELACIÓN DE GUIAS DE TRABAJO UTILIZADAS}

ARXIU D'ETNOGRAFIA I FOLKLORE DE CATALUNYA:

1922 Manual per a recerques d'Etnografia de Catalunya. Barelona. Tipografia Carreras.

ATENEO CIENTIFICO, LITERARIO Y ARTISTICO DE MADRID:

1901 Cuestionario, 1901-1902 (Información promovida por las Sección de Ciencias Morales y Políticas en el curso 1901-1902, circular y cuestionario). Madrid. Impresora de la Real Casa.

MAESTRE ALFONSO, J.:

1974 La investigación en Antropologia Social Madrid. Itsmo.

MIRALLES i MONTSERRAT, J.:

1978 Qüestionari sobre Història i Cultura Popular de Mallorca. (separata) Fontes Rerum Balearum. vol. II. Mallorca.

MURDOCK, G. et alii:

1966 Guia para la clasificación de datos culturales. Washington.

\section{BIBLIOGRAFÍA BÁSICA}

\section{ALLUÉ MARTINEZ, Marta:}

1980 Siemprevivas e inmortales. Rituales e instituciones funerarias en las comarcas de Tarragona. Tarragona. Fac. Lletres. Tesis de $\mathrm{Li}$ cenciatura.

(en prensa) Aproximación a la bibliografía socio-antropológica en torno a la 
muerte. En: Actas del II Congreso de Antropologia Madrid. Universidad Autónoma de Madrid.

AMADES, Joan:

1969 Folklore de Catalunya. Costums i creences. Barcelona. Selecta. (Reedición en 1980). La más importante recopilación etnográfica sobre las creencias y costumbres en torno a la muerte en Catalun. ya ilustradas con una colección de urondallesn y refranes propios de las noches de velatorio o de las fiestas de difuntos.

ARIĖS, Philippe:

1975 Essais sur l'experience de la mort en Occident. Paris. Seuil. Apor. tación histórico-sociológica valiosa sobre la evolución de las actitudes ante la muerte.

CASAS GASPAR, Enrique:

1947 Costumbres españolas de nacimiento, noviazgo, casamiento y muerte. Madrid. Escélicer. Información folklórica de caràcter general poco sistematizada pero rica en aspectos descriptivos.

\section{CASTAÑÓN, Luciano:}

1976 Supersticiones y creencias en Asturias. Salinas (Asturias). Ayalga. Datos sobre la creencia en la Santa Compaña y supersticiones en torno a ella.

GUIART, Jean (comp.):

1979 Les hommes et la mort. Rituels funeràires à travers le monde. Paris. Le Sycomore. Colección de artículos específicos en torno a rituales, creencias, cantos fúnebres, luto tipo de enterramiento y festividades de difuntos, tanto en comunidades históricas como en sociedades primitivas y tradicionales, sistematizados por áreas geográficas. Incluye un capitulo dedicado a las costumbres funerarias en Aragón, Navarra y Catalunya. Interesante puesto que vehicula la via del análisis comparativo.

HERTZ, Robert (1909)

1970 Contribution à une étude sur la répresentation collective de la mort. En: Sociologie religieuse et folklore. Paris. P.U.F. Primera contribución al estudio de la fase liminal del ritual funerario. La base etnográfica del análisis la establece sobre la sociedad Do. gon.

HOYOS SAINZ, Luis de

1944
Folklore español del culto a los muertos. En: Revista de Dialecto. logia y tradiciones populares. (Madrid) 1 (1-2):30-53. Unico etnó grafo español que intentó sistematizar la temática funeraria a nivel de Península Ibérica. La divide en tres bloques a modo de "áreas culturales funerarias" cada una de las cuales reune una serie de rasgos que definen las costumbre y el culto a los muertos en el sector delimitado.
RISCO, Vicente:

1946 Creencias gallegas. La procesión de las ánimas y las premoniciones de muerte. En: Revista de Dialectologia y Tradiciones Popula. res. (Madrid) 2: (3): 380-429

THOMAS, Louis-Vincent:

Anthropologie de la mort. Paris. Payot. Primera, y casi única siste matización de la problemática de la muerte desde un punto de visma estudio comparativo de la ta antropologico. Se fundamenta en muerte entre la sociedad negro-africana y la sociedad occidental muerte entre las puntos de vista: actitudes, creencias, ritos, etc.

TURNER, Victor:

The Ritual Process. Chicago, Aldine. Aportación teórica necesa ria para la comprensión de las fases de los ritos de paso.

VAN GENNEP, Arnold:

1964 Les rites de passage. Paris. Mouton. Planteamiento teórico en torno a las fases y características simbólicas de los ritos de paso. no a las fases Du berceau à la tombe. En: Manuel de Folklore Français Contem porain. Paris. A. Picerd. Aportan Amades. zada en Catalunya

VIOLANT i SIMORRA, Ramón:

1959 Cultura espiritual: la vida social i religiosa. Etnografia de Reus i la seva comarca. Reus. La Rosa de Reus.

ZIEGLER, Jean:

1976 Los vivos y la muerte. Madrid. Siglo XXI. Desde un punto de vista más bien sociológico, el autor realiza una comparación intercultural sobre el morir y la muerte en dos sociedades: la de la diáspora africana en Brasil y la occidental. 